\title{
Analysis on the Development of Green Bonds in China
}

\author{
Yuchen Wang ${ }^{1, *}$ \\ ${ }^{1}$ Tianjin University of Commerce, Tianjin 300400, China \\ *Corresponding author. Email: 1603236918@qq.com
}

\begin{abstract}
Green bonds have broad prospects in the Chinese market, occupying an important position in the development of green finance, and have an important impact on China's transition to a low-carbon economy. This article discusses the development of China's green bond market from the issuance of green bonds in 2016 to the present. The author analyzed in details the changes and impact of the green bond market caused by the outbreak of the 2020 epidemic. Through analysis, there are still shortcomings in the further development of green bonds, such as the lack of a unified certification standard, and the lack of an authoritative platform to provide comprehensive green bond information as well as scientific and executable green bond standards, which is combined with actual conditions. Besides, the author also provided policy recommendations for the further development of China's green bond market.
\end{abstract}

Keywords: Green bonds, Climate bonds, Green investment, Green finance.

\section{INTRODUCTION}

With the accelerated development of modern industry, people are also facing challenges such as rapid depletion of ecological resources and deterioration of the ecological environment while obtaining convenience. The main natural disasters common in the world today are global warming caused by the greenhouse effect, air pollution caused by industrial products and chemical emissions, and energy shortages caused by overexploitation of resources. Governments of various countries are committed to formulating and implementing environmental laws and regulations to promote economic growth while reducing environmental damage. Public expenditures play an important role in this regard. However, there are still problems in the global environment. Therefore, green finance, as an important driving force based on environmental, economic and social sustainable development, has become an emerging trend in the development of the global financial industry. As the largest developing country in the world, China has faced environmental problems, such as air pollution, water pollution, and desertification in recent years. These problems not only restrict economic development, but also seriously affect people's daily lives. In the face of increasing pollution and ecological damage, different entities choose to take measures to cope with it. The state encourages the development of new industries, the market has high expectations for green enterprises, and investors have increased their concern and awareness of the environment; these moves provide good opportunities for the development of green industries and green financial systems. This article reviews the development history and advantages of China's green bond market. The author analyzes the changes caused by the epidemic based on the performance of China's green bonds during the 2020 COVID-19 pandemic, and explains the current status and development direction of the green bond market. Combining with the shortcomings of green bonds under the influence of China's economic policies, the author also provides some suggestions, hoping to provide some help to future investors and researchers. 


\section{THE THEORETICAL BACKGROUND OF GREEN BOND DEVELOPMENT}

\subsection{Definition and Characteristics of Green Bonds}

In recent years, green bonds have developed rapidly around the world, which become more and more important in climate change and sustainable development financing. The development potential and space of the global market for green bonds are still good, and more and more funds are invested in sustainable development and cleaner production through green bonds. Green bonds are any type of bond tool, whose proceeds will be partially or fully applied to new or existing qualified green projects [1]. The adoption of the Paris Climate Agreement in 2015 promoted the development of the green bond market. Although initially focused on green investment, especially low-carbon and climate change investment, it was later expanded to fully defend green bonds in 2016.

OECD and others believe that "green bonds" are bonds designed to finance environmental projects. Unlike traditional bonds, green bonds identify the green industries and green projects that will be financed before issuance. Then funds are allocated to green projects, assets or companies and the subsequent use of the funds is strictly controlled, in order to ensure transparency and fairness of the funds. Public institutions and private companies can release funds and increase financing by issuing green project bonds and refinancing [2].

\subsection{The Development of Green Bonds in China}

As a new financing instrument that has emerged in international financial markets in recent years, green bond is not innovations in transaction structure or financing model, but in the use of proceeds. In 2007, the European Investment Bank (EIB) issued the world's first green bond to finance renewable energy projects based on climate change mitigation targets, and in China, the first green bond was issued by Xinjiang Goldwind Technology Co. on July 16, 2015 [3]. On December 15, 2015, China's central bank issued the Notice on Issuing Green Financial Bonds in the Interbank Securities Market, which can be seen as the institutional level of China's green bond market. In 2016, the total amount of green bonds issued in the Chinese financial market reached US\$36.2 billion, accounting for $39 \%$ of the total global green bond issuance (US\$81 billion), making China the world's largest green bond market at that time [4]. According to the 2018 China Green Bond Market Research Report, financial institutions dominated the green bond market in China, with green corporate bond issuance jumping to the second place, excluding the issuance of short-term financial bonds. With the implementation of the registration system and the increasing improvement of industry standards, China's green bond issuance continues to heat up. 276 "labeled" green bonds have been issued in China since 2020, with a total issuance size of $\$ 219.361$ billion. Bond issuers are also becoming more diverse: sovereigns, municipalities, commercial banks, multilateral development finance institutions, corporations and many other types of investors are involved.

\section{ANALYSIS OF ADVANTAGES OF GREEN BONDS}

The main reason for the rapid adoption of green bonds is that green bonds have very obvious advantages. In terms of financial performance, Curley believes that green bonds have flexible payment terms [5], which can improve credit quality and achieve the goal of reducing costs based on the long-term timeliness of the project. Gianfrate and Peri analyzed that, because the cost of less than certified tokens is higher than the issuance interest paid by the issuer, green bonds can effectively increase the value of the company in the short term [6]. Tang believes that when a company issues green bonds to benefit existing shareholders, the liquidity of the company's stock will be greatly improved [7], and the initial issuance will have a greater impact than the re-issuance. Clapp and Flammer believe that green investment bonds can effectively make up for the financing gap of capital-intensive institutional projects [8]. They believe that green bonds can be used to finance capital-intensive institutional projects. After the issuance of green bonds, the environmental performance of companies has been improved, prompting Carbon emissions from production activities have decreased, and the number of green patents and green investors has increased.

Since its standardization in 2016, China's green bond market has become the world's largest green bond market and has gradually attracted the attention of relevant parties. Qu Zhenghong found that the level of corporate environmental information affects the financing cost by affecting 
the liquidity of bonds and the expected risks of investors [9]. Increasing the level of information can increase the liquidity of bonds, reduce the expected risks of investors. Among the financing costs of bond issuance, the impact of non-monetary environmental information is more significant. Green bonds have a $1 \%$ interest rate advantage over traditional bonds. This advantage mainly depends on the scale of issuance, maturity, issuer's capital, return on net assets, and market interest rates. Chen Danning used an event-driven approach to study the short-term market impact of green bond issuance and found that green bond disclosure had a significant positive impact on issuer capital [10], which led to a strong interest of Chinese investors in green bond disclosure and corporate environmental information.

The authors argue that the current development advantage of China's green bonds also stems from political support and leadership and a change in the country's development philosophy. As people's understanding of ecological civilization deepens in China, green development has become one of the five major development concepts. Currently, Chinese governments at all levels have started to establish green development funds and are promoting the development of green finance and establishing a green investment and financing system. This change in development philosophy, policy support and guiding principles has become an important driving force for the development of green finance. Meanwhile, domestic and international financial institutions and companies are actively participating in the market and the demand for green bonds and funds is increasing. The development of the green bond market is now not only limited to domestic financial institutions and companies issuing bonds in the domestic market, but also fully extended to financial institutions and companies issuing foreign currency green bonds in foreign markets. Energy efficiency, carbon reduction, ecology and environmental protection are now popular investment targets for private equity and venture capital funds.

\section{GREEN BOND ISSUANCE UNDER THE COVID-19}

According to data related to green bonds, since the standardized construction of China's green bond market, from 2016 to the end of 2020, a total of 907 green bonds were issued, with a total value of RMB 1,143.686 billion (see Figure 1). The number of China's green bond ranks first in the world, which occupies $48.6 \%$, or 536.5 billion yuan in the world.

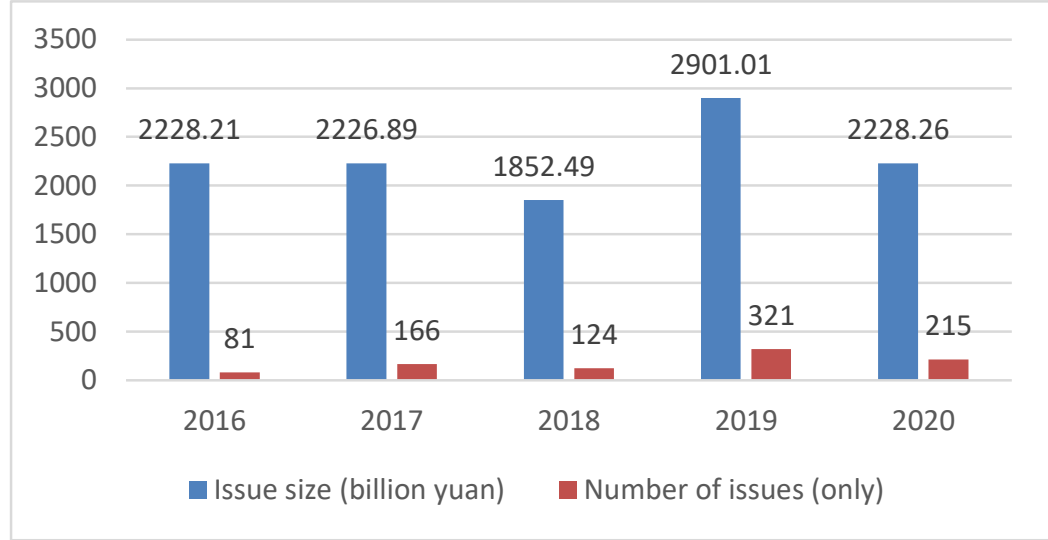

Figure 1 Number and scale of green bonds issued in China from 2016 to the end of June 2020 [11].

Among them, the COVID-19 in 2020 will shake the financial market and seriously affect the trade chain. Green development and climate risk prevention are facing new situations, but green finance has become the driving force for responding to the economic impact of the COVID19 epidemic. In 2020, a total of 153 institutions issued 215 green bonds, with a total amount of 228.26 billion yuan. At the same time, the epidemic has changed the scale of bond issuance, which is embodied in the following aspects.

\subsection{Changes in Green Bonds Under COVID-19}

\subsubsection{Sharply Decline of Green Financial Bond Trading Volume}

Green financial bonds are characterized by a relatively large amount of one-time issuance, which is the main face type of China's green bond market from 2016 to 2018. In 2019, the issuance of green 
financial bonds began to decline, and the trend intensified in 2020. In 2020, 9 Chinese financial institutions issued a total of 11 green financial bonds, accounting for $5.1 \%$ of the total number of green bonds. The number of issuance during the year decreased by $64.5 \%$, and the number of issuances during the year decreased by $65.4 \%$; the total issuance was 27.20 billion yuan, accounting for the total issuance $12.2 \%$ of the total, and the number of issuance decreased by $67.4 \%$ during the year. Including green bonds/bonds issued by financial companies, the total issuance of green bonds issued by financial companies was 38.65 billion-yuan, accounting for $17.4 \%$.

During the epidemic, green bond volume size decreased because the market was more affected by the COVID-19 and the number of issues in the global green bond market was rapidly decreasing. Financial bonds, previously issued on a larger scale, have seen the most significant drop due to the scope of funds used. Since the impact of the epidemic on enterprises was first reflected in liquidity, the requirement to earmark funds for green projects green bonds are not a good investment choice. In addition, the issuance cycle also limits the volume of green financial bonds issued and traded. As commercial banks issued more green financial bonds from 2016 to 2017, they become mature and are paying off one after another and starting to reserve projects in preparation for re-registering new green financial bonds, thus resulting in fewer new green financial bonds issued in 2020 and a significant drop in turnover. However, with the new batch of green financial bonds being approved and issued, it is expected that the issuance and turnover of green financial bonds will gradually increase in the future.

\subsubsection{Largest type: Green Corporate Bonds (from the Perspective of Bonds Issuance and Value)}

As shown in "Table 1", the cumulative issuance of green corporate bonds, green corporate bonds, green bonds and green asset-backed securities in 2020 will be 73.21 billion yuan, 47.44 billion yuan, 40.3 billion yuan and 22.26 billion yuan, respectively, increased by $-12.2 \%,-0.5 \%, 22.9 \%$ and $37.5 \%$, respectively. Different types of green bonds have fallen at different rates, but the issuance of green corporate bonds is 73.21 billion yuan, ranking first $(33.0 \%)$ among the types of green bonds, and the issuance of corporate bonds is 91 yuan, also ranking first (41.7). \%). The growth of green bond products continued the established trend, with the issuance of mid-term green bonds increasing by RMB 4.23 billion during the year, an increase of $14.2 \%$.

Table 1. Summary of non-publicly issued green bonds in 2020 (only, billion yuan, \%)

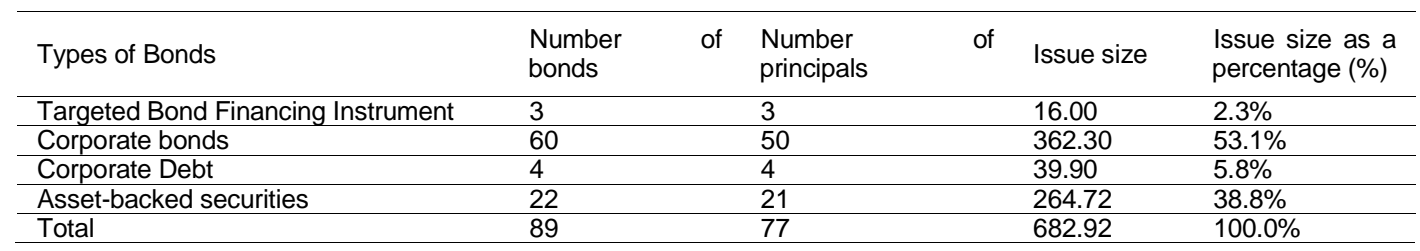

\subsubsection{The Increase of Market Participants and Market Activity}

In 2020, a total of 153 companies in China's green bond issuance market issued 215 green bonds, with a total issuance amount of 222.826 billion yuan, a decrease of $23.0 \%$ from the amount issued in 2019 (290.11 billion yuan). The number of units increased from 150 in 2019 to 153 , a yearon-year increase of $2.0 \%$; the number of debts increased to 106 , a year-on-year increase of $33.0 \%$.

\subsubsection{The Increasingly Importance of Issuing Green Bonds in Non-financial Markets}

For green enterprises, green bonds from nonfinancial enterprises are a direct financing method, which is not only more efficient in terms of capital use, but also more convenient in terms of registration and issuance. Although financial institutions are the main issuers in China's green bond market, the scale of green bond issuance by non-financial enterprises is relatively small. With the gradual introduction of green bond policies for non-financial enterprises and the vigorous promotion of green bonds by relevant departments, non-financial enterprises are paying more and more 
attention to the issuance of green bonds, and the scale and variety of issuance are increasing. The direct issuance of green bonds led by non-financial enterprises not only improves the efficiency of financing and capital utilization, but also motivates non-financial enterprises to take the initiative to disclose information as direct debt payers, so that the development of the financial and environmental fields forms a virtuous circle. By 2020, the total issuance of non-financial green bonds, including green corporate bonds, green corporate bonds, green financial securities and asset-backed green securities will increase. In 2020, green nonfinancial bonds will dominate in issuance and issuance. The total issuance is 183.51 billion yuan, a year-on-year decrease of $8.2 \%$. The total issuance accounts for $82.6 \%$ of the total market, which is higher than $68.4 \%$ in 2019 . The number of issued is 196, a year-on-year increase of $19.5 \%$.

\subsection{China's Green Bond Issuance Scale and Policies During the COVID-19}

The COVID-19 broke out in early January 2020. The impact on green bonds was relatively small in the first quarter. The more obvious decline occurred in May, but the issuance volume and scale in June showed a trend of picking up again. The impact of the epidemic on the issuance of green bonds is not significant. Considering the situation that green bonds may be affected by seasonal patterns, a comparison of green bond issuance scale shows that the scale of green bond issuance in 2017-2020 all peaked in April and then declined. While China National Railways Limited issued RMB 80 billion of green bonds in 2020, the measure pushed the green bond issuance scale up sharply. However, there is no significant impact of the epidemic on China's green bond issuance scale from the overall perspective.

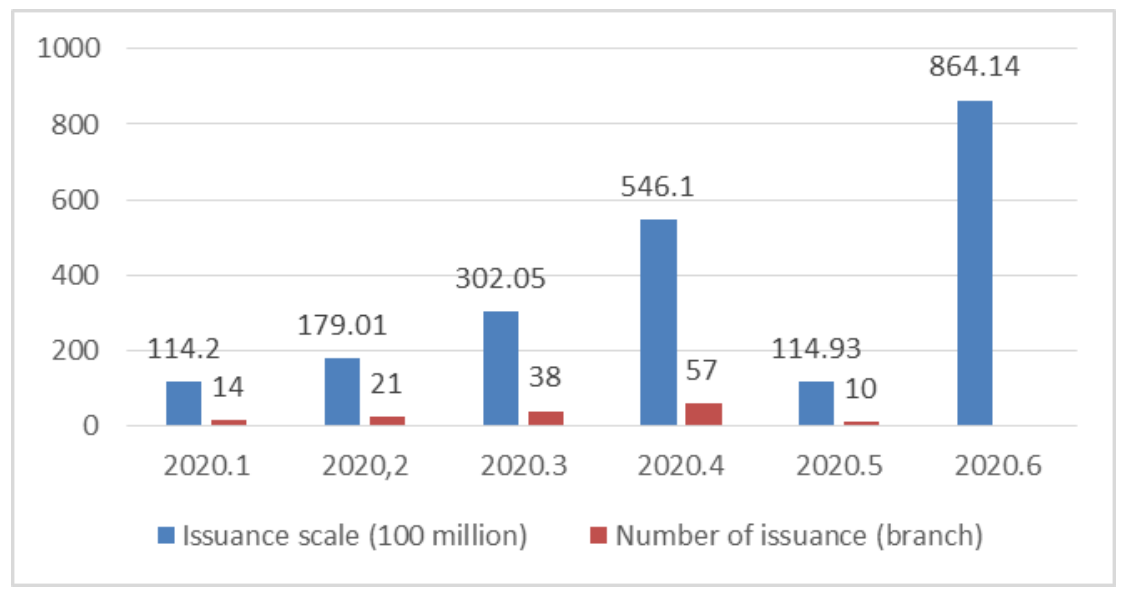

Figure 2 The number and scale of domestic green bond issuance in China from the beginning of 2020 to the end of June 2020.

China's corporate bonds and corporate bonds were issued by 58 companies during the epidemic, accounting for a relatively large proportion. Considering the current overall situation of China's green bond market, enterprises have shown some enthusiasm and eagerness to issue green bonds, which has gradually shifted the main force in the green bond market to the real economy.

\section{DISCUSSION}

\subsection{Weaknesses in the Development of China's Green Bonds}

\subsubsection{The Needs of Improving Institutional Mechanism}

China's green bonds do not have a unified standard, and even if the newly issued policies have a certain mitigation effect on this problem to a certain extent, they still have not completed the standard system and show a low similarity compared to international standards. In addition, green bond-related information is not fully disclosed, and it is difficult to detect and evaluate 
the collection, sorting, approval, and disclosure of such information. It is necessary for the state to optimize relevant channels to facilitate the public's access to information.

\subsubsection{The Issuing Body Which Is Relatively Single in Composition}

By collecting data related to green bond issuance information from 2016 to 2020 , this paper draws the conclusion that state-owned enterprises are still the main issuers of green bonds, and the issuance of private enterprises lags far behind in number and scale. However, in the process of China's economic development, private enterprises play an important role and influence, and participate in the process of economic transformation to low carbon. Therefore, in order to promote the development of green bonds and other green industries, China should focus on promoting the development of private enterprises.

\subsubsection{Product Integration Which Needs to Be Strengthened}

In the relevant policy documents related to the promotion of green bonds and other green products, provinces have shown different scales of development. Among them, green bonds are developing rapidly in scale compared to green credit and are stronger than products such as green insurance. This phenomenon reflects the lack of good integration among green products and the lack of innovation in the types of green financial products in China.

\subsection{Recommendations for the Development of Green Bonds in China}

The development of China's green bonds is a government-led "top-down" model. The following suggestions may help the government to better control and develop China's green bonds.

Through the use of advanced technologies such as financial technology to create a platform that specifically provides comprehensive information on green bonds, combined with the technological means of advancing artificial intelligence and big data to disclose relevant information in a timely and effective manner. This not only facilitates researchers and investors to obtain timely information, but also more accurately measures and evaluates the costs, risks and benefits of green bonds. It also provides convenient conditions for technicians to track and inspect the issuance of green bonds.

Enterprises of different nature and scale can develop and improve the incentives and penalties for issuing green bonds for their own specific conditions. It is necessary to formulate incentive and subsidy measures suitable for enterprises and push them to be implemented faster and better. For example, for green bonds during the epidemic, companies can extend the period for repaying the principal and interest of green bonds. At the same time, severe measures can be taken to punish violations related to the issuance of green bonds, in order to prevent others from doing so. The government can play a leading role as a model. After all, as the issuer, the government has a stronger fault tolerance rate and the ability to bear risks than enterprises.

It is necessary to cultivate investors' awareness of green investment, enrich and improve related investment channels, and increase publicity and public support. Enterprises and governments can develop more types of investment projects, such as the establishment of special green bonds during the epidemic period. Additionally, the government can improve green projects for epidemic prevention, and provide investors with more alternative and reliable investment channels.

\section{CONCLUSION}

This article mainly introduces the definition and characteristics of green bonds, the development history and advantages in China. The author focuses on the analysis of the development status of green bonds in China during the new crown pneumonia epidemic, and puts forward suggestions based on the development deficiencies, and provides the future development direction of green bonds Provide a reference. This paper summarizes and compares the development history of green bonds in China, and combines further research and analysis by scholars on the advantages of green bonds. The impact of the COVID-19 in 2020 on China's green bonds is analyzed in focus. Additionally, some suggestions are made to address the shortcomings of existing green bonds, with the aim of providing a modest contribution to the better development of China's green bond market. Due to the limitations of the author's academic level and the length of the paper, the research in this article is still insufficient for investors' reference. For example, this article lacks more data to evaluate the issuance and trading volume of green bonds of 
specific companies, so it cannot give the issuance of green bonds in different regions to help researchers conduct further research. It is hoped that in future research, relevant articles can be published to adjust and improve existing deficiencies.

\section{AUTHORS' CONTRIBUTIONS}

This paper is independently completed by Yuchen Wang.

\section{ACKNOWLEDGMENTS}

First and foremost, I would like to show my deepest gratitude to my teachers and professors in my university, who have provided me with valuable guidance in the writing of this thesis. Further, I would like to thank my friends and parents for their encouragement and support.

\section{REFERENCES}

[1] ICMA. (2018). Green bond principles. https://www.icmagroup.org/green-social-andsustainability-bonds/green-bond-principlesgbp/. Accessed 24 Dec 2020.

[2] OECD et al. (2016). Green bonds: country experiences, barriers and options. OECD/ICMA/CBI/China GFC. http://unepinquiry.org/wpcontent/uploads/2016/09/6_Green_Bonds_Co untry_Experiences_Barriers_and_Options.pdf. Accessed 3 Feb 2020

[3] Lin L, et al. (2014). A look at CGN Wind energy's notes linked to the carbon trade. Financial Market Research, 6, 83-87.

[4] Climate Bonds Initiative and China Central Depository \& Clearing Co., Ltd. (2017). China green bond market 2016. Accessed January 19, 2019, from https://www.chinabond.com.cn/resource/1472/ 1488/1505/18472/41498/63390/146165612/14 84726438037986159279.pdf.

[5] Curley, Michael (2014). Finance Policy for Renewable Energy and a Sustainable Environment [J]. Crc Press.

[6] Gianfrate G, Peri M (2019). The green advantage: Exploring the convenience of issuing green bonds [J]. Journal of Cleaner Production, 127-135.
[7] Tang D Y, Zhang Y (2020). Do shareholders benefit from green bonds $[\mathrm{J}]$. Journal of Corporate Finance, 2020.

[8] Flammer C (2019). Green Bonds: Effectiveness and Implications for Public Policy [J]. National Bureau of Economic Research, 2019: 95-128.

[9] Qu Z H (2017). Research on the Impact of Environmental Information Disclosure Quality on Green Bond Financing Cost [D]. Harbin Institute of Technology. (in Chinese)

[10] Chen D N (2018). Stock price effect of green bond issuance by Chinese listed companies [J]. Journal of Shanxi University of Finance and Economics, 40(S2): 35-38. (in Chinese)

[11] Li Y Y (2020). Research on the development of green bonds under the impact of the new crown pneumonia epidemic [J]. Financial Economics, 09: 65-70+77. (in Chinese) 